\title{
El Padul, un enclave natural y un registro sedimentario excepcionales. Sus humedales y turberas
}

\author{
Jon Camuera Bidaurreta | Dpto. de Estratigrafía y Paleontología, U. de Granada \\ María José Ramos Román| Dpto. de Estratigrafía y Paleontología, U. de Granada \\ Gonzalo Jiménez Moreno|Dpto. de Estratigrafía y Paleontología, U. de Granada \\ José Antonio López Sáez | Instituto de Historia, CSIC \\ Francisca Alba Sánchez| Dpto. de Botánica, U. de Granada
}

URL de la contribución <www.iaph.es/revistaph/index.php/revistaph/article/view/3916>

\section{RESUMEN}

Los humedales y turberas de la cuenca de El Padul (provincia de Granada) constituyen un enclave natural singular y único, uno de los más importantes de Andalucía y la única zona húmeda de origen endorreico en Granada. En estos sistemas palustres encuentran cobijo una gran variedad de especies de flora y fauna, algunas de ellas amenazadas o en riesgo de extinción. En esta depresión, los sedimentos llegan a alcanzar un espesor de más de 100 metros y hasta 1 millón de años de antigüedad, lo que permite considerar el registro paleoambiental de El Padul como uno de los más importantes de Europa occidental y de todo el Mediterráneo. Su valor paleontológico es excepcional, al haberse encontrado restos de mamut intercalos entre niveles de turba, los cuales representan la población más occidental y meridional de restos de estos proboscídeos.

\section{Palabras clave}

El Padul | Granada (Provincia) | Humedales | Paleontología | Turberas | Patrimonio natural | Paleontología | 

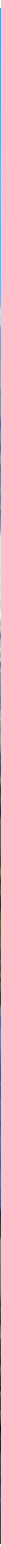

Lagunas y turberas de El Padul con Sierra Nevada al fondo | foto Francisca Alba Sánchez, de todas las del artículo si no se indica lo contrario 


\section{GEOGRAFÍA Y ORIGEN}

La depresión de El Padul, con una extensión aproximada de 327 hectáreas, es una subcuenca endorreica y asimétrica situada en la parte más meridional de la cuenca de Granada, a unos $20 \mathrm{~km}$ al sur de la ciudad de Granada, ocupando la zona más septentrional del valle de Lecrín entre 720 y 760 metros de altitud. Queda limitada al norte y noreste por las estribaciones suroccidentales de Sierra Nevada, al sur y sureste por las lomas que alcanzan la sierra de Albuñuelas, cerrándose al sur por los materiales depositados por el río Dúrcal.

Desde un punto de vista geológico, la depresión de El Padul es una fosa tectónica subsidente, limitada por dos sistemas de fallas de dirección noroeste-sureste. Esta cuenca se colmató durante el Cuaternario por materiales detríticos (limos y arcillas) que fueron rellenándola en forma de dos sistemas de abanicos aluviales de sedimentos provenientes de la erosión de Sierra Nevada; los cuales alternan con otros de origen lacustre como arenas y depósitos de turba en la zona noroeste, la que mayor subsidencia tuvo durante el Cuaternario actuando como dopocentro o área con depósitos de mayor expesor. Al quedar cerrada al sur por el cono de deyección del río Dúrcal, en esta depresión, que constituye el drenaje natural de la cuenca de Granada, se formó un lago más o menos somero, donde posteriormente se produjo la formación de turba. La turbera resultante cubrió un área de alrededor 400 hectáreas.

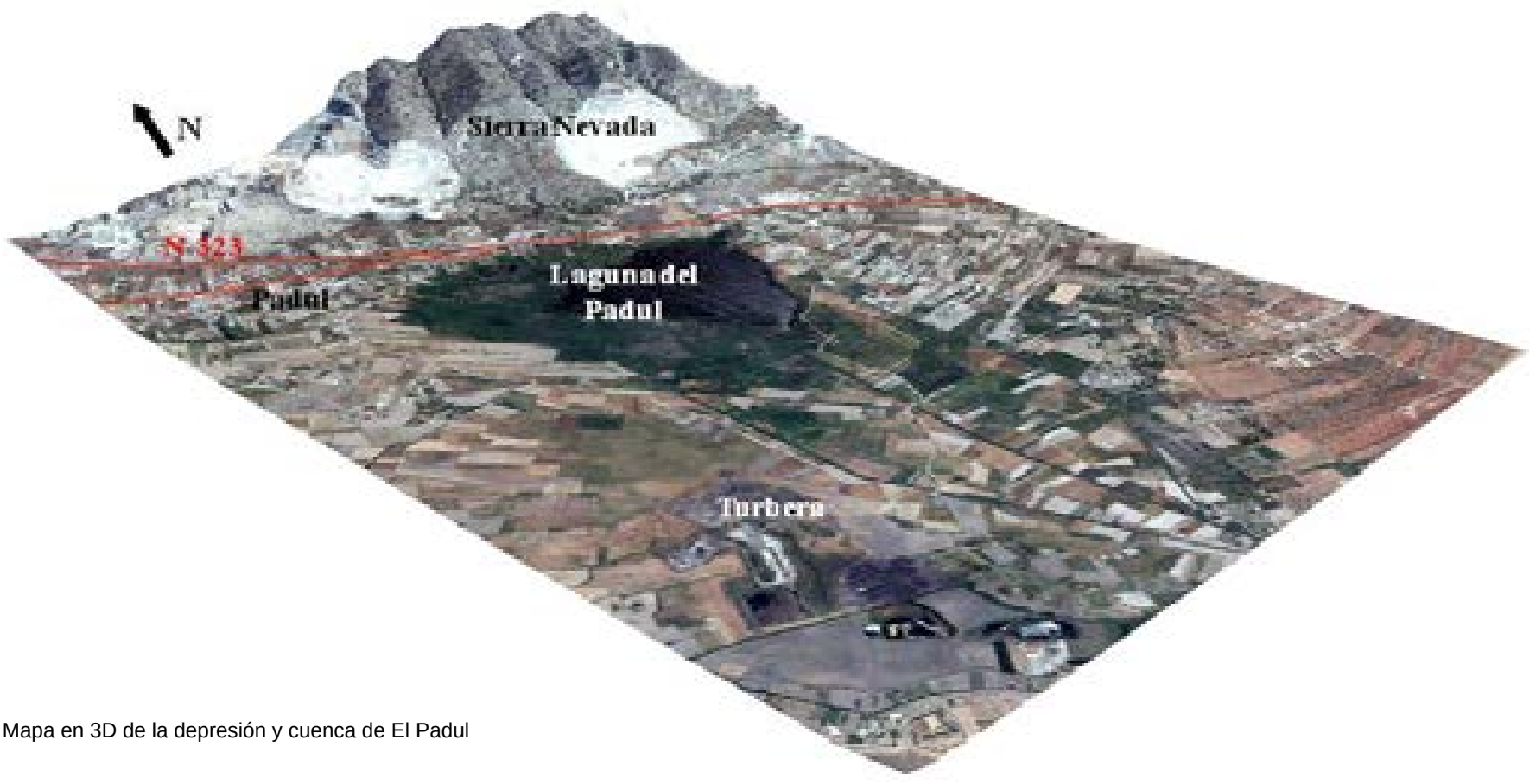


Los humedales y turberas actuales de El Padul son, por tanto, los restos de dicho sistema fluvial de inundación. Desde antaño, estos paisajes han sido enormemente transformados por la actividad humana, que ha aprovechado la singularidad de este enclave permanentemente encharcado para la extracción industrial de turba y como zona de cultivos. La depresión se caracteriza hoy por la abundancia de canales de drenaje (conocidos como madres), construidos entre los siglos XVIII y XIX con el objetivo de drenar y desecar la antigua laguna, tanto para el desarrollo de actividades agrícolas como para evitar focos infecciosos de paludismo. Los canales no han conseguido desecar por completo la laguna, apareciendo pequeños reductos lagunares en sectores donde se extrae la turba, que conservan una fauna y flora singulares.

\section{VALORES NATURALES Y PALEONTOLÓGICOS}

El humedal de El Padul es uno de los más importantes del sureste peninsular, la única zona húmeda de origen endorreico de la provincia de Granada, y probablemente la turbera más extensa del Mediterráneo suroccidental. Este humedal está protegido como un área de reserva (grado A) dentro del parque natural de Sierra Nevada, siendo considerado de especial interés por el Convenio Ramsar de protección de humedales desde el año 2006. Fue incluido en el Inventario de Espacios Naturales Protegidos de Andalucía en el año 1989, y desde 2004 figura en el de Humedales. Desde 1979 es considerado también una zona de especial protección para las Aves (ZEPA) así como un lugar de importancia comunitaria (LIC), dentro de Sierra Nevada, según la Directiva Hábitat 92/43/CEE.

A pesar de las numerosas agresiones que han sufrido, los humedales y turberas de El Padul constituyen la mejor representación de sistemas palustres de la provincia de Granada, englobando la mayor extensión de carrizales de Andalucía, tras los de Doñana, en los cauces permanentes y en la orilla de canales; en los cuales también son frecuentes otros helófitos como las eneas y los juncales (MARTÍNEZ PARRAS; PEINADO, 1983). En este humedal se desarrollan comunidades vegetales dulceacuícolas de lentejas de agua que llegan a tapizar por completo aguas remansadas y eutróficas; poblaciones densas de carófitos y macrófitos acuáticos como elodeidos, ninfeidos, miriofílidos y batráchidos en estanques y lagunas de aguas frescas y limpias, a veces profundas, donde sobresalen las flores del lirio amarillo y de los berros de agua. En suelos turbosos, en cambio, se desarrollan comunidades de cárices de elevada cobertura y mediana talla (PÉREZ RAYA; LÓPEZ NIETO, 1991).

En cuanto a la fauna, este humedal sustenta numerosas aves que utilizan las lagunas como lugar de reproducción, descanso o invernada, habiéndose 

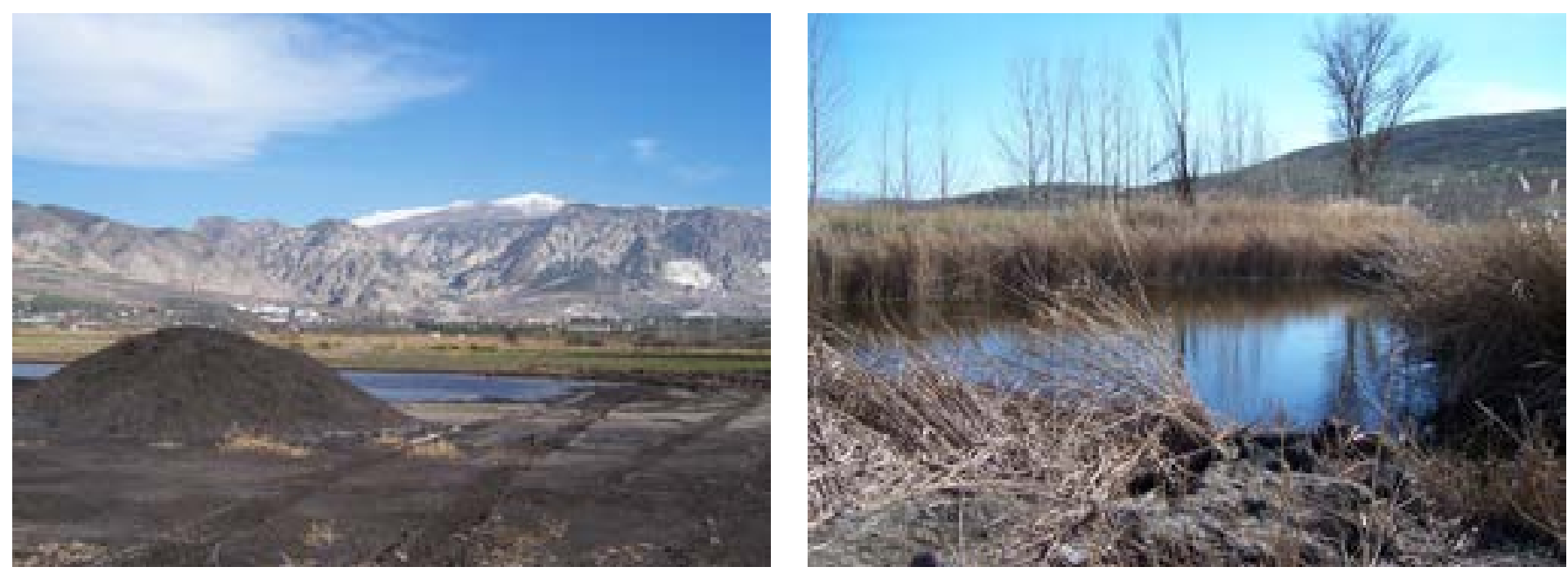

Detalle de la explotación de turba en las turberas de El Padul

Carrizales (Phragmites australis) de El Padul, los más extensos de Andalucía tras los de Doñana contabilizado hasta 158 especies, muchas de las cuales están contempladas en el Libro Rojo de Vertebrados Amenazados de Andalucía de 2001 o en el anexo I de la Directiva de Aves 79/409/CEE. Entre ellas destacan el aguilucho lagunero occidental y el pálido, el ánade real y el silbón, el avefría, el avetorillo común, el calamón común, la focha común, la garceta común, la garza real, el martín pescador, el pechiazul, el porrón común, el zapullín chico, o la escasa polluela chica. Dentro de los anfibios, destacan especies como la salamandra común (considerada vulnerable en Andalucía) o la ranita meridional (contemplada en el anexo IV de la Directiva Hábitat 92/43/ CEE), o los también frecuentes gallipato y sapo común. Entre los reptiles encontramos al galápago leproso (vulnerable en España e incluido en los anexos II y IV de la Directiva Hábitat citada), la culebra viperina, el lagarto ocelado y las lagartijas colilarga y cenicienta. En cuanto a los peces, en este humedal viven casi en exclusividad cachos, un ciprínido ibérico endémico de tamaño medio con una distribución restringida. En sus aguas y entre su vegetación destaca la presencia de un micromamífero incluido en la Lista Roja de Especies Amenazadas de la Península Ibérica, la musarañita; además de ratas de agua.

Además de sus valores naturales, los humedales y turberas de El Padul aunan una riqueza paleontológica y geológica excepcionales, constituyendo un registro fósil único y singular en el seno del Mediterráneo suroccidental. Recientemente Álvarez Lao; Kahlke; García, et ál. (2009) publicaron la presencia de restos de mamut (Mammuthus primigenius) en algunos horizontes de la turba de El Padul, caso de fragmentos mandibulares, molares, fémur, falanges y colmillos. A pesar de que los mamuts de El Padul no difieren morfológicamente de individuos contemporáneos de otras regiones de Europa, estos hechos revelan la importancia adicional de esta localidad con respecto a la biogeografía de estos proboscídeos, al representar su población 

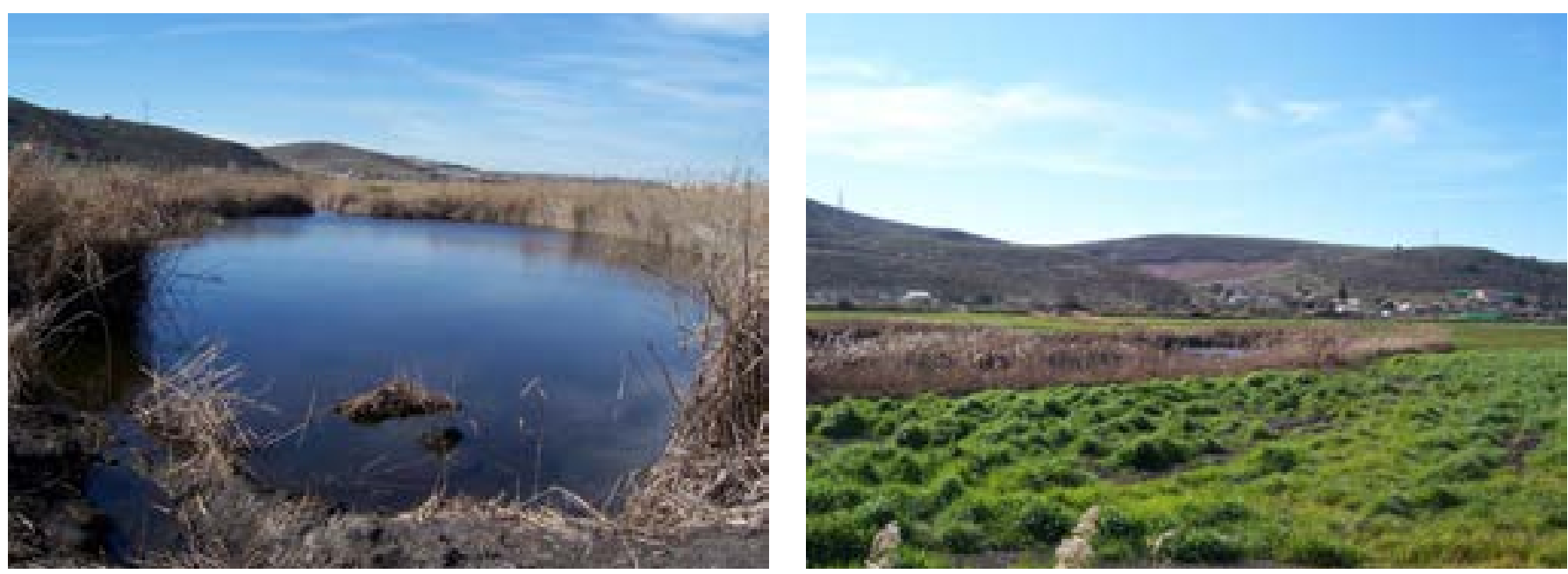

Reductos lagunares de El Padul, los cuales aúnan una gran biodiversidad

más occidental y meridional dentro de una amplia distribución holártica. Las dataciones mediante radiocarbono de dichos restos fósiles indican que los La mayor parte de los humedales y turberas de El Padul se dedican a zonas de cultivo mamuts estuvieron presentes en El Padul entre 40 y 30 mil años atrás, conviviendo con bisontes esteparios, ciervos y caballos de talla mediana. Esta expansión meridional de los mamuts lanudos que llegaron a El Padul parece correlacionarse con períodos de condiciones climáticas particularmente secas y frías durante la última glaciación, en paralelo con la extensa distribución de ambientes esteparios donde se alimentarían. Estudios biogeoquímicos detallados realizados sobre los mismos restos demuestran que los mamuts lanudos no permanecieron constantemente en El Padul, sino que principalmente vivían en el oeste de la península ibérica y sólo en momentos más fríos y áridos migraban hasta aquí, en una zona de refugio natural de aquella época. Por entonces, la temperatura media anual en Padul era de 10-11 ํ (GARCÍA ALIX; DELGADO HERTAS; MARTÍN SUÁREZ, 2012).

\section{UN REGISTRO PALEOAMBIENTAL ÚNICO}

A pesar de que la mayor parte de la zona de reserva está hoy ocupada por terrenos de labor, al menos unas 60 hectáreas corresponden a áreas pantanosas y turbosas que se sitúan principalmente en las áreas más deprimidas. El relleno de la cuenca de El Padul llega a alcanzar un espesor de hasta 107 metros en su zona oeste, siendo uno de los registros sedimentarios del Pleistoceno más emblemáticos de la península ibérica y de Europa occidental (NESTARES; TORRES, 1998). De acuerdo al estudio realizado por Ortiz; Torres; Delgado (2004) en El Padul suceden dos escenarios hidrológicos muy marcados: desde su base hasta aproximadamente el metro 60, es decir entre 1 millón (1 Ma) y 400 mil años (400 ka) atrás, dominan sedimentos detríticos como gravas, arenas y lutitas, las cuales serían indicativas 

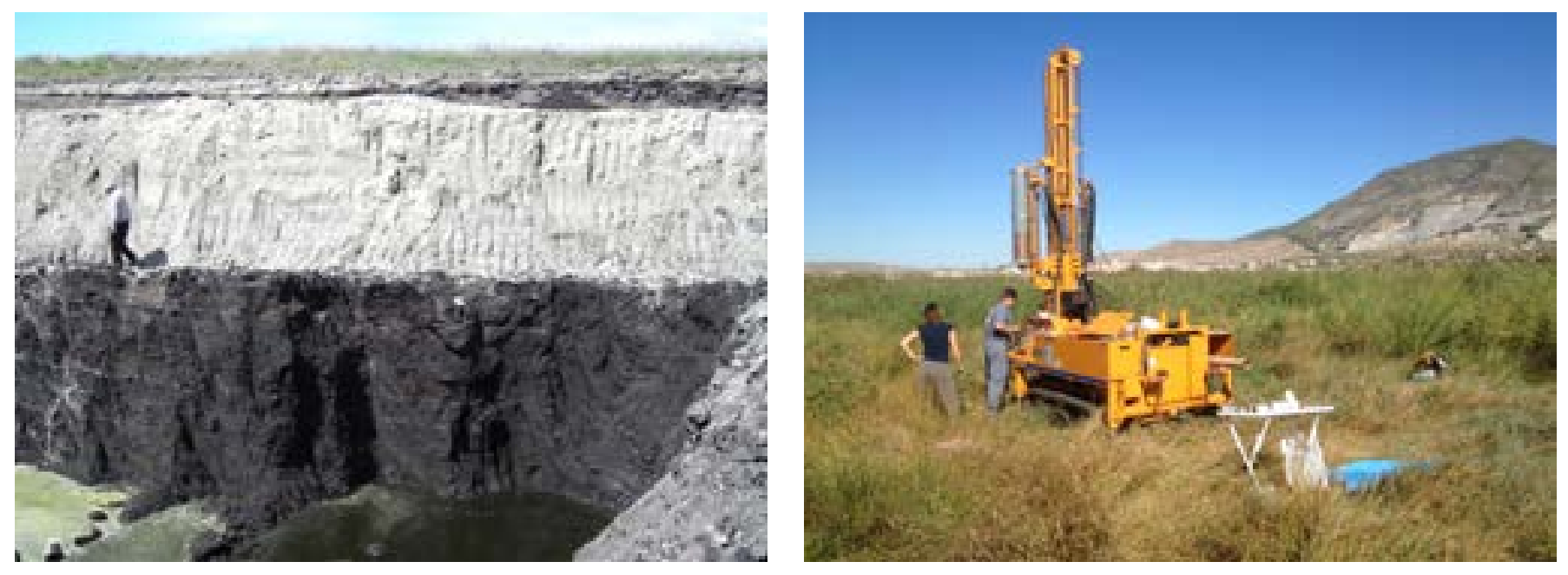

Explotación de turba. Se aprecian los sedimentos más recientes depositados en la laguna de Padul. Los colores blanquecinos son sedimentos carbonatados y los oscuros turbas y arcillas ricas en materia orgánica vegetal. Estos cambios de sedimentación se deben a cambios en el clima y el medioambiente en la laguna y sus alrededores

Imagen de uno de los sondeos sedimentarios en la turbera de El Padul, la cual tiene aproximadamente un millón de años de antigüedad | foto Gonzalo. Jiménez Moreno

de la existencia en dicho marco temporal de un entorno lacustre abierto, de recarga continua y relativamente profundo. En contraste, en los 60 metros superficiales, desde hace $400 \mathrm{ka}$ hasta $4.5 \mathrm{ka}$, la cuenca de El Padul se convirtió en un pantano en donde se produjo la sedimentación de turba, con la entrada principal de agua proveniente de aportaciones de aguas subterráneas, generándose una turbera que ha permanecido prácticamente hasta la actualidad. Desde la Universidad de Granada se ha realizado un nuevo sondeo de 43 metros (desde hace aproximadamente 300 mil años hasta la actualidad) que muestra alternancias entre diferentes litologías (turbas, carbonatos y arcillas) que permiten dilucidar cambios en el nivel del lago asociado a variaciones paleoambientales.

Las turberas son ecosistemas húmedos, formaciones vegetales propias de zonas inundadas de agua, muy pobres en nutrientes y con una importante falta de oxígeno, donde la materia orgánica se descompone gradualmente dando lugar a un sedimento orgánico llamado turba. Constituyen verdaderos islotes de biodiversidad, ya que en ellas confinan su hábitat ciertas especies vegetales y animales, algunas de las cuales son verdaderas reliquias de la época glacial. En Europa, el uso principal de las turberas durante siglos ha sido agropecuario, pues si son bien manejadas figuran entre las tierras agrícolas más productivas disponibles. Además, al ser ecosistemas muy frágiles y escasos, factores de origen antrópico como la explotación para la obtención de turba, así como la tendencia a la aridificación en el sur de Europa, los han conducido a un estado de regresión muy peligroso.

La formación de una turbera requiere de ciertos requisitos geoambientales, un clima y condiciones edáficas particulares. En primer lugar, un sustrato rocoso impermeable y un suelo con mal drenaje, que en El Padul está representado por dolomías mesozoicas, de tal manera que el agua de lluvia o pro- 
cedente por escorrentía superficial se acumule en las zonas de vaguada y quede estancada. En segundo lugar, un clima fresco y húmedo, que evite un exceso de evapotranspiración y la conservación de la materia vegetal descompuesta que constituye la turba. La formación de turberas es debida a la lenta descomposición de la materia orgánica. El paso de los años va produciendo una acumulación de turba que puede alcanzar muchos metros de espesor, a un ritmo de crecimiento que varía en cada región. Gracias a ello, las turberas constituyen una de las principales herramientas para el estudio de la vegetación y el clima del pasado. Al no descomponerse por completo la materia orgánica, en la turba se conservan maderas semifosilizadas, restos vegetales, granos de polen y otros microrrestos. Los sondeos de estos depósitos sedimentarios permiten la extracción de dichos materiales, que pueden ser datados cronológicamente de acuerdo a la profundidad en que hayan sido encontrados.

En la turbera de El Padul se han llevado a cabo numerosos estudios estratigráficos y palinológicos así como de otros biomarcadores isotópicos y geoquímicos (MENÉNDEZ AMOR; FLORSCHÜTZ, 1962, 1964; PONS; REILLE, 1988; FLORSCHÜTZ; MENÉNDEZ AMOR; WIJMSTRA, 1991; RÍO; GONZÁLEZ VILA; MARTÍN, 1992; VALLE HERNÁNDEZ et ál., 2003; ORTIZ; TORRES; DELGADO, 2004, 2010). El control cronológico de la secuencia sedimentaria de El Padul proviene del análisis de muestras por radiocarbono, uranio/torio, racemización de aminoácidos y paleomagnetismo. Hasta la fecha existen diversos datos cronológicos de diferentes testigos sedimentarios, pero todos parecen estar de acuerdo en que la edad geológica de la secuencia sedimentaria de la cuenca de El Padul iría desde finales del Pleistoceno temprano (1 Ma) hasta la actualidad; es decir, un registro sedimentario único en el seno del Mediterráneo.

Dichos estudios han permitido reconstruir la dinámica paleoambiental de la cuenca de El Padul, particularmente la historia de la vegetación y la variabilidad del clima durante el último millón de años. A lo largo de este periodo se han documentado hasta seis episodios áridos entre los que se intercalan cinco más húmedos. Durante las fases secas (1 Ma-800 ka, 630-450 ka, 405-360 ka, 235-170 ka, 135-95 ka, 25-10 ka) se produciría la regresión de las masas forestales y el predominio de una vegetación abierta de pastos de gramíneas y elementos de carácter estépico; mientras que en las fases húmedas (800-630 ka, 450-405 ka, 360-235 ka, 170-135 ka, 95-25 ka) la tendencia sería justamente la contraria, dominando bosques de pinos y de caducifolios así como una rica flora de macrófitas acuáticas 


\section{BIBLIOGRAFÍA}

- ÁlVAREZ LAO, D. J.; KAHLKE, R. D.; GARCÍA N.; MOL, D. (2009) The Padul mammoth finds-On the southernmost record of Mammuthus primigenius in Europe and its southern spread during the Late Pleistocene. Palaeogeography, Palaeoclimatology, Palaeoecology, n. ${ }^{\circ} 278,2009$, pp. 57-70

- FLORSCHÜTZ, F.; MENÉNDEZ AMOR, J.; WIJMSTRA, T. A. (1971) Palynology of a thick Quaternary succession in Southern Spain. Palaeogeography, Palaeoclimatology, Palaeoecology, n. ${ }^{\circ} 10,1971$, pp. 233-264

- GARCÍA ALIX, A.; DELGADO HUERTAS, A.; MARTÍN SUÁREZ, E. (2012) Unravelling the Late Pleistocene habitat of the southernmost woolly mammoths in Europe. Quaternary Science Reviews, n. ${ }^{\circ} 32,2012$, pp. $75-85$

- MARTÍNEZ PARRAS, J. M.; PEINADO, M. (1983) Estudio botánico de los ecosistemas de la Depresión de Padul (Granada). Collectanea Botanica, n. ${ }^{\circ} 14$, 1983, pp. 317-326

- MENÉNDEZ AMOR, J.; FLORSCHÜTZ, F. (1962) Un aspect de la végétation en Espagne méridionale durant la dernière glaciation et I'Holocène. Geologie en Mijnbouw, n. ${ }^{\circ}$ 41, 1962, pp. 131-134

- MENÉNDEZ AMOR, J.; FLORSCHÜTZ, F. (1964) Results of the preliminary palynological investigation of samples from a $50 \mathrm{~m}$ boring in southern Spain. Boletín de la Real Sociedad Española de Historia Natural (Geología), n. ${ }^{\circ} 62,1964$, pp. 251-255

- NESTARES, T.; TORRES, T. (1998) Un nuevo sondeo de investigación paleoambiental del Pleistoceno y Holoceno en la turbera de Padul (Granada, Andalucía). Geogaceta, n. ${ }^{\circ} 23,1998$, pp. 99-102

- ORTIZ, J. E.; TORRES, T.; DELGADO, A. et ál. (2004) The palaeoenvironmental and palaeohydrological evolution of Padul Peat Bog (Granada, Spain) over one million years, from elemental, isotopic and molecular organic geochemical proxies. Organic Geochemistry, n. ${ }^{\circ}$ 35, 2004, pp. 1243-1260

- ORTIZ, J. E.; TORRES, T.; DELGADO, A. et ál. (2010) Palaeoenvironmental changes in the Padul Basin (Granada, Spain) over the las $1 \mathrm{Ma}$ based on the biomarker content. Palaeogeography, Palaeoclimatology, Palaeoecology, n. ${ }^{\circ} 298,2010$, pp. 286-299

- PÉREZ RAYA, F.; LÓPEZ NIETO, J. M. (1991)

Vegetación acuática y helofítica de la Depresión de
Padul (Granada). Acta Botánica Malacitana, n. ${ }^{\circ} 16$, 1991, pp. 373-389

- PONS, A.; REILLE, M. (1988) The Holocene and Upper Pleistocene pollen record from Padul (Granada, Spain): a new study. Palaeogeography, Palaeoclimatology, Palaeoecology, n. ${ }^{\circ} 66,1988$, pp. 243-263

- RÍO, J. C. DEL; GONZÁLEZ VILA, F. J.; MARTIN, F. (1992) Variation in the content and distribution of biomarkers in two closely situated peat and lignite deposits. Organic Geochemistry, n. ${ }^{\circ} 18,1992$, pp. 67-78

- VALLE HERNÁNDEZ, M.; RIVAS CARBALLO, M. R. et ál. (2003) Interpretación paleoecológica y paleoclimática del tramo superior de la turbera de Padul (Granada, España). Polen, n.. 13, 2003, pp. 85-95 